\title{
Stromal control of chronic lymphocytic leukemia cells
}

This article was published in the following Dove Press journal:

Research and Reports in Biology

13 September 2013

Number of times this article has been viewed

\section{Paul Faustin Seke Etet ${ }^{\prime}$ \\ Armel Herve Nwabo \\ Kamdje ${ }^{2}$ \\ Jeremie Mbo Amvene ${ }^{2}$ \\ Yousef Aldebasi ${ }^{3}$ \\ Mohammed Farahna' \\ Lorella Vecchio ${ }^{4}$}

'Department of Basic Health Sciences, College of Applied Medical

Sciences, Qassim University, Buraydah, Saudi Arabia; ${ }^{2}$ Department of

Medicine, University of Ngaoundere, Ngaoundere, Cameroon; ${ }^{3}$ Department of Optometry, College of Applied Medical Sciences, Qassim University, Buraydah, Saudi Arabia; ${ }^{4}$ Laboratory of Cytometry, Institute of Molecular Genetics, CNR, University of Pavia, Pavia, Italy
Correspondence: Paul Faustin Seke Etet Qassim University, College of Applied Medical Sciences, Department of Basic Health Sciences, PO Box 6699,

5 I 452 Buraydah, Saudi Arabia

Tel +96663800050 ext 4I55

$\mathrm{Fax}+96663801628$

Email paul.seke@gmail.com
Abstract: In the ongoing efforts to develop therapies against chronic lymphocytic leukemia (CLL), stromal factors allowing malignant cells to escape spontaneous and chemotherapymediated apoptosis, giving way to relapses, have been abundantly investigated. Bone marrow adherent cell types, collectively referred to as stromal cells, appear to be key players in such escape, mainly because CLL malignant cells, which rapidly undergo spontaneous apoptosis when cultured in vitro, survive, migrate, and resist cytotoxic agents in co-culture with bone marrow stromal cells. CLL displays variable clinical courses according to well-defined prognostic factors induced on malignant B-cells (CLL cells) or expressed by the transformed bone marrow stromal microenvironment. Particularly, a critical pathogenic role is played by proinflammatory factors, adhesion molecules, and signaling molecules involved in cell fate and stemness, such as Notch, Wnt, sonic Hedgehog, phosphoinositide 3-kinase (PI3K), protein kinase B (Akt), and the B-cell CLL/lymphoma 2 (Bcl-2) family of regulator proteins. As herein discussed, these molecules probably form a complex network favoring CLL cell survival, proliferation, and chemoresistance to anticancer therapy. Characterizing the sets of signaling pathways involved in the interactions between stromal cells and CLL cells may provide new tools for CLL clinical phenotyping and for re-sensitizing chemotherapy resistant cells.

Keywords: chronic lymphoblastic leukemia, CLL, signaling pathways, cancer, stromal cells

\section{Introduction}

B-cell chronic lymphocytic leukemia (CLL), the most common lymphoproliferative disorder, ${ }^{1}$ is characterized by the clonal expansion of mature antigen-stimulated B-cells (cluster of differentiation $19^{+}\left[\mathrm{CD} 19^{+}\right] / \mathrm{CD}^{+} / \mathrm{CD} 23^{+}$) in the blood and secondary hematopoietic organs, including lymphoid tissues, and bone marrow (BM), in close contact with stromal microenvironment. ${ }^{1,2}$ The disease displays variable clinical courses according to well-defined prognostic factors induced on malignant B-cells (CLL cells) or expressed by the transformed BM stromal microenvironment. ${ }^{3,4} \mathrm{~A}$ critical role in the pathogenesis is played by: (1) proinflammatory factors and adhesion molecules that would be involved in the migration of CLL cells into the BM stroma, including for instance the cell surface glycoprotein $\mathrm{CD} 44$, tumor necrosis factor-related factors, stromal cell-derived factor 1 (SDF-1) also termed as C-X-C motif chemokine 12 (CXCL12) and its receptor C-X-C motif receptor 4 (CXCR4); and (2) signaling molecules involved in fundamental cellular functions associated with tumorigenesis, including proliferation, differentiation, and apoptosis, such as phosphoinositide 3-kinase (PI3K), protein kinase B (Akt), Notch, Wnt, sonic Hedgehog (Hh), and the B-cell CLL/ lymphoma 2 (Bcl-2) family of regulator proteins. ${ }^{5-8}$ Early and emerging experimental 
evidence suggests that CLL malignant B-cells retain the capacity to respond to most of these molecules in vivo and in vitro, pointing out interesting opportunities for devising therapies for this currently incurable disease. However, the precise mechanisms of action of such molecules are not well understood, and they appear to interact in a complex fashion (Figure 1). The present review summarizes and discusses the current understanding of the molecular interactions between CLL cells and the BM stroma.

\section{BM stromal cells support the proliferation, survival, and chemoresistance of CLL cells}

BM stroma derives from mesenchymal stromal cells (MSCs), adult multipotent nonhematopoietic stem cell precursors which support the maintenance and engraftment of hematopoietic stem cells. ${ }^{9,10}$ MSCs reside in virtually all organs containing connective tissue, ${ }^{9}$ including lymphoid organs. ${ }^{10}$ Co-culture with BM stromal cells allows normal B-cells to escape from spontaneous apoptosis. ${ }^{11,12}$ Not surprisingly, early studies revealed that human BM stromal cells prevent apoptosis and support the survival of CLL cells in vitro, ${ }^{13-15}$ and mouse stroma allowed long-term proliferation of human leukemia cells, ${ }^{16}$ indicating a key role of factors released or induced by stromal cells in the maintenance and proliferation of CLL cells. CLL cells are also affected by these cell types and by the microenvironment in vivo. For instance, CLL cell growth is under the control of signals from T-cells and stromal cells in the pseudofollicular proliferation centers. Stromal cells would contribute to CLL cell long-term support through bidirectional interactions ${ }^{17}$

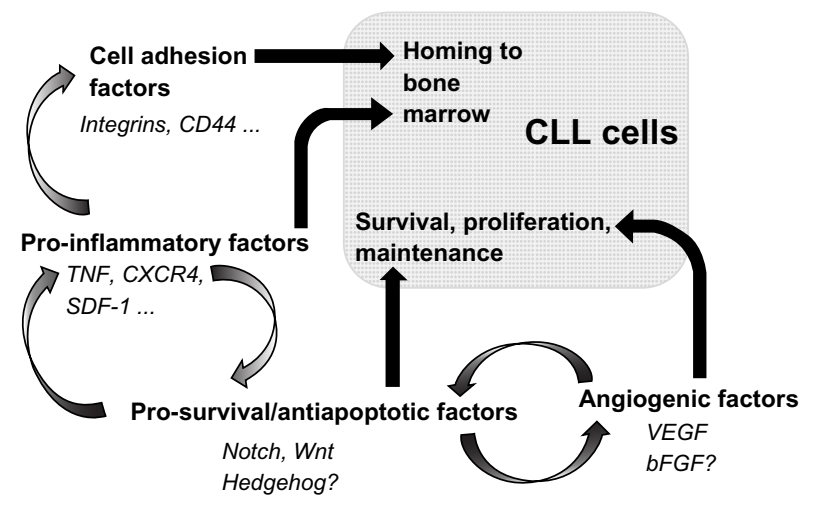

Figure I The interactions of the bone marrow stromal environment with CLL B-cells are complex. Note the crosstalk between antiapoptotic factors and angiogenic factors or proinflammatory factors.

Abbreviations: bFGF, basic fibroblast growth factor; CD44, cluster of differentiation 44; CLL, chronic lymphocytic leukemia; CXCR4, C-X-C motif receptor 4; SDF-I, stromal cell-derived factor I; TNF, tumor necrosis factor; VEGF, vascular endothelial growth factor. resulting in the activation of various survival pathways, including Wnt and Notch, as discussed further (see "Protooncogenic factors").

Moreover, CLL cells are also closely associated with follicular dendritic cells in both the early phase of BM involvement and in the lymph nodes. ${ }^{18}$ Such association would play a key role in the pathogenesis of B-cell lymphoma, mainly in malignant cell proliferation and survival. ${ }^{11}$ Furthermore, a subset of blood mononuclear cells related to BM stromal cells, that can protect CLL cells from apoptosis in vitro, was described. ${ }^{11,19}$ Strikingly, these cells, termed as "blood-derived nurse-like cells," are rarely found in healthy donor peripheral blood, ${ }^{11}$ indicating differences in composition and cell population ratios between normal and CLL-affected blood. These observations suggest that direct cell-cell interactions of CLL cells with accessory cells such as BM stromal cells or follicular dendritic cells create a microenvironment that protects CLL cells from apoptosis, with significant clinical implications. Also in agreement with this hypothesis, other reports have suggested that patterns and extents of malignant infiltrates correlate with CLL clinical stage and prognosis. ${ }^{20,21}$ Notably, CLL cell co-culture with MSCs protects the first against apoptosis induced by anticancer drugs, including cyclophosphamide, fludarabine, bendamustine, prednisone, and hydrocortisone..$^{415,22-29}$ Thus, tissue homing of malignant blood cells has both diagnostic and therapeutic importance. Unraveling the precise mechanisms governing cell-cell interactions between the infiltrating CLL cells and resident BM stromal cells is therefore of crucial importance for designing efficient therapeutic approaches. Major reports from clinical trials and various emerging therapeutic approaches in relapsed or refractory CLL are summarized in Table 1.

\section{Proto-oncogenic factors}

In the ongoing efforts to develop therapies against CLL, stromal factors allowing CLL cells to escape spontaneous and chemotherapy-mediated apoptosis have been abundantly investigated, among which the proto-oncogenic factors Notch, Hh, and Wnt.

\section{Notch}

The Notch family of transmembrane proteins consists of four receptors (Notch1-4) and five ligands, which are the structural homologs of Drosophila ligands Serrate (Jagged1 and Jagged2) and Delta (Delta-like ligand or DLL1, 3, and 4). Human BM MSCs express DLL3, 4, and Jagged1 in basal conditions. ${ }^{8}$ Experimental data suggest Notch involvement in 
Table I Relapsed/refractory chronic lymphocytic leukemia treatment: recent reports from clinical trials

\begin{tabular}{|c|c|c|}
\hline & Mechanism of action & Preliminary/final results \\
\hline \multicolumn{3}{|l|}{ Molecules } \\
\hline Acadesine (AICA-riboside) & AMP-activated protein kinase activator & $\begin{array}{l}\text { Acceptable safety profile but results variable probably due } \\
\text { to the small population and the range of doses tested }{ }^{102}\end{array}$ \\
\hline $\begin{array}{l}\text { T-cell chimeric antigen } \\
\text { receptors }\end{array}$ & $\begin{array}{l}\text { Redirect the specificity to } \\
\text { tumor-associated antigens }\end{array}$ & $\begin{array}{l}\text { Early-phase trials are demonstrating impressive antitumor effects; } \\
\text { multicenter trials needed }{ }^{103}\end{array}$ \\
\hline Idelalisib (GS-IIOI, CAL-I0I) & Delta-specific PI3K inhibitor & $\begin{array}{l}\text { Early clinical studies revealed a rapid and sustained reduction } \\
\text { in lymphadenopathy with a transient lymphocytosis }{ }^{104}\end{array}$ \\
\hline Ibrutinib (PCl-32765) & Inhibitor of BTK & $\begin{array}{l}\text { High frequency of durable remissions in relapsed or refractory } \\
\text { patients }{ }^{105,106}\end{array}$ \\
\hline Perifosine (KRX-040I) & Akt inhibitor & Stabilized the disease with an Akt-independent mechanism ${ }^{107}$ \\
\hline SFII 26 (LY294002/SFIIOI) & Pan-PI3K/mTORC inhibitor & Well tolerated; best response in patients with advanced disease ${ }^{108}$ \\
\hline \multicolumn{3}{|c|}{ Chemo/immunotherapy regimens } \\
\hline OFAR2 (modified OFARI) & $\begin{array}{l}\text { Regimen: oxaliplatin, fludarabine, } \\
\text { cytarabine, and rituximab }\end{array}$ & $\begin{array}{l}\text { Significant antileukemic activity in Richter's syndrome and relapsed/ } \\
\text { refractory cases; post-remission therapy had favorable outcomes }{ }^{109}\end{array}$ \\
\hline $\begin{array}{l}\text { Fludarabine }+ \text { cytarabine }+ \\
\text { reduced-intensity conditioning }\end{array}$ & $\begin{array}{l}\text { Suggested as conditioning regimen before } \\
\text { allogeneic hematopoietic stem cell } \\
\text { transplantation in patients with poor-risk CLL }\end{array}$ & $\begin{array}{l}\text { Early reports indicate high response rate }(93 \%) \text { and favorable } \\
\text { progression-free survival and overall survival. Needs large cohort } \\
\text { studies }^{110}\end{array}$ \\
\hline $\begin{array}{l}\text { Combinations of chlorambucil } \\
\text { fludarabine, rituximab, and } \\
\text { alemtuzumab }\end{array}$ & $\begin{array}{l}\text { Regimens: chlorambucil, fludarabine, } \\
\text { fludarabine }+ \text { rituximab, fludarabine }+ \\
\text { alemtuzumab, fludarabine }+ \text { rituximab + } \\
\text { alemtuzumab }\end{array}$ & $\begin{array}{l}\text { Data support the use of chlorambucil as an acceptable treatment } \\
\text { for older patients, while rituximab is beneficial regardless } \\
\text { of age }{ }^{\mid I, I / 2}\end{array}$ \\
\hline Lenalidomide + rituximab & $\begin{array}{l}\text { Lenalidomide: immunomodulatory drug. } \\
\text { Rituximab: chimeric monoclonal } \\
\text { antibody targeting CD20 }\end{array}$ & $\begin{array}{l}\text { Active in patients with recurrent CLL; warrants further } \\
\text { investigation in a larger cohorts }\end{array}$ \\
\hline $\begin{array}{l}\text { Rituximab }+ \text { fludarabine }+ \\
\text { total body irradiation }\end{array}$ & $\begin{array}{l}\text { Suggested as conditioning regimen } \\
\text { before allogeneic hematopoietic stem } \\
\text { cell transplantation in advanced CLL }\end{array}$ & $\begin{array}{l}\text { Early reports indicate that it is feasible, well tolerated, and allows } \\
\text { better outcomes }{ }^{1 / 4}\end{array}$ \\
\hline $\begin{array}{l}\text { Rituximab + recombinant } \\
\text { interleukin-2I }\end{array}$ & $\begin{array}{l}\text { Anti-CD20 antibody and recombinant } \\
\text { human interleukin- } 2 \text { I }\end{array}$ & $\begin{array}{l}\text { Well tolerated; durable complete remissions in a small subset } \\
\text { of patients; studies in larger cohorts needed }{ }^{115}\end{array}$ \\
\hline Rituximab + bendamustine & Anti-CD20 antibody and an alkylating agent & Effective and safe in patients with previously untreated CLL ${ }^{116}$ \\
\hline
\end{tabular}

Abbreviations: Akt, protein kinase B; AMP, adenosine monophosphate; BTK, Bruton's tyrosine kinase; CD20, cluster of differentiation 20; CLL, chronic lymphocytic leukemia; mTORC, mammalian target of rapamycin complex; PI3K, phosphoinositide 3-kinase.

stem cell survival and resistance to apoptosis. For instance, Notch and hypoxia-related proteins may interact to play key roles in the survival of both normal and previously irradiated human skin cells. ${ }^{30}$ Similarly, some hypoxia-related proteins and proinflammatory molecules may induce the maintenance of hematopoietic stem cells in an undifferentiated state via Notch signaling activation. ${ }^{31,32}$

Besides, experimental evidence also suggests that Notch signaling plays a key role in CLL cell resistance to apoptosis. Notch receptors and ligands are constitutively expressed both on CLL cells from patients ${ }^{33}$ and on CLL cells co-cultured with BM stromal cells. ${ }^{34,35}$ A cohort study showed that Notch1 PEST domain mutation is of prognostic relevance in CLL patients, though in a minority of cases $(5.3 \%) .{ }^{36} \mathrm{In}$ a further study, the prevalence of such Notch1 mutational activation increased with disease severity, reaching up to $31 \%$ of cases toward Richter's transformation, ${ }^{37}$ pointing out Notch 1 aberrant activation as a bad prognosis predictor. In a recent cohort study where single strand conformation analysis was performed in 209 CLL patients, mutations of Notch1 and TP53 genes seem to be independent predictive markers for worse outcome in CLL patients, ${ }^{38}$ emphasizing the contention that Notch1 mutations is a novel risk marker in CLL. Another recent study addressing Notch pathway activation in Notch1-unmutated cases revealed the existence of interplay between Notch and nuclear factor- $\mathrm{\kappa B}(\mathrm{NF}-\mathrm{\kappa B})$ pathways, ${ }^{39}$ the latter being also one of the constitutively activated pathways in CLL. Considering that both NF- $\mathrm{KB}$ regulators and Jagged were both unmutated even in presence of genetic lesions in the NF- $\mathrm{\kappa B} /$ Notch loop, it appears that the Jagged-mediated interplay between NF- $\mathrm{KB}$ and Notch is independent of such lesions. Thus, therapeutic approaches targeting both Notch and NF- $\mathrm{KB}$ pathways simultaneously should be investigated in CLL.

Similarly, Notch signaling would also trigger other classes of signaling molecules. Evidence from genome-wide expression studies suggests the existence of a large number of Notch-regulated genes ${ }^{40}$ For instance, interactions between 
Notch1 and tumor suppressor protein 53 (p53) signaling were reported..$^{41}$ Notch signaling ability to regulate integrin expression (eg, $\alpha_{L} \beta_{2}, \alpha_{4} \beta_{1}$ ) in CLL cells was also reported. ${ }^{24}$ Considering that $\alpha_{4} \beta_{1}$ integrin and its ligand vascular cellular adhesion molecule 1 (VCAM1) are known to be obligatory proteins in the adhesion of B-precursors to stromal cells, ${ }^{42}$ the present findings further supports a role for integrins in CLL pathogenesis (see also "Cell adhesion factors: cytokines"). In addition, constitutive activation of Jagged 1-Notch signaling increased CLL cell survival following NF- $\mathrm{KB}$ activity increase and the expression of various inhibitors of apoptosis (eg, cellular inhibitor of apoptosis 2, X-linked inhibitor of apoptosis). ${ }^{34} \mathrm{BM}$ MSC-mediated CLL cell survival in vitro was also promoted by Notch1, 2, 4, and $\alpha_{4} \beta_{1}$ integrin signaling, as well as chemoresistance to various anticancer drugs, including the alkylating agents bendamustine and cyclophosphamide, the purine analog fludarabine, and the glucocorticoid drugs prednisone and hydrocortisone..$^{24,26}$ Such chemoresistance was at least in part p53, Bcl2, and NF- $\kappa B$ dependent. ${ }^{43}$ The activation of Notch1, 2, and 4 would also trigger the release of the proinflammatory chemokine interleukin-7 (IL-7) receptor on CLL cells ${ }^{24}$ (see also "Inflammatory factors: cytokines"). Altogether, these observations suggest that Notch signaling triggered by proto-oncogenic factors of both microenvironmental and systemic origin can be a key pathogenic event in CLL.

Of particular interest for therapy, emerging evidence indicates that compounds that interfere with Notch signaling efficiently induce apoptosis in CLL cells, including $\gamma$-secretase inhibitors $I_{,}{ }^{34,44}$ and Notch-signaling inhibitors acting at the transcription factor level. ${ }^{45} \gamma$-Secretase inhibitors I apoptotic activity was associated with a reduction in $\mathrm{NF}-\kappa \mathrm{B}$ and $\mathrm{p} 53$ activities. Another recent study showed that $\gamma$-secretase inhibitors I induce apoptosis through at least three mechanisms: proteasome inhibition, endoplasmic reticulum stress increase, and Notch downregulation. ${ }^{46}$

\section{$\mathrm{Hh}$}

In vertebrates, the $\mathrm{Hh}$ family is represented by three ligands (desert Hh, Indian Hh, and sonic $\mathrm{Hh}$ ) and two Hh receptors, which are homologs of the Drosophila transmembrane protein Patched (Ptch1 and Ptch2). Hh receptors are negative regulators of the signal transducer Smo. Hh family also includes the zinc finger protein Gli and some transcription factors homologs of Drosophila protein Cubitus interruptus. ${ }^{47,48} \mathrm{Hh}$ family plays various roles in cell cycle regulation and other cell fate determining events. ${ }^{49} \mathrm{However}$, the role of $\mathrm{Hh}$ signaling in normal and malignant hematopoiesis is controversial.
Although self-renewal defects were reported in some studies, ${ }^{50,51}$ absences of changes in hematopoietic phenotypes following Hh abrogation were also reported. ${ }^{52,53}$

Studies in CLL cells reveal an involvement of Hh family in the pathogenesis of the disease. Indian Hh, the most commonly expressed Hh ligands in hematopoietic stem cell progeny, ${ }^{51}$ prolonged CLL cell survival in the stromal microenvironment. ${ }^{53}$ Poor clinical outcome has been reported in CLL patients overexpressing $\mathrm{Hh}$ signaling negative regulator SUFU and zinc finger proteins Gli1 and 2. ${ }^{53}$ Thus, defects in the intrinsic pathway, as well as increased ligand expression and probably any other change in the tumor stromal microenvironment causing Hh signaling impairment in CLL cells may negatively affect disease clinical features and therapy outcome. Interestingly, although Hh signaling targeting had no effect on normal hematopoiesis in adult mice, ${ }^{54}$ selective inhibition of Gli proteins - the key regulators of Hh signaling - abrogated BM stromal cell-mediated CLL resistance to fludarabine-induced apoptosis. ${ }^{52}$ Similarly, Hh signaling inhibition also increased cyclopamine-induced apoptosis in CLL cells, ${ }^{52}$ strongly indicating that Hh signaling targeting can be a valid approach for increasing chemotherapy outcome in CLL. Thus, Hh signaling targeting should be studied further in regards to the important therapeutic implications. Considering the redundancy of survival pathways activated by stromal cells in leukemia cells, which is probably one of the major causes of the failure to develop efficient therapies for many hematologic malignancies, it would be interesting to evaluate the impact of Hh signaling targeting on CLL clinical features in vivo.

\section{Wnt}

Wnt molecules are a family of secreted proteins playing key roles in the control of cell-cell interactions, cell growth, and cell fate. ${ }^{6,55}$ Canonical Wnt signaling pathway plays a key role in hematopoietic stem cell maintenance. ${ }^{56}$ Following exposure to low levels of Wnt ligands, mitosis and proliferation are observed in MSCs ${ }^{57}$ Furthermore, human BM MSCs synthesize the Wnt pathway inhibitor Dickkopf-related protein 1, which may increase their proliferation rate. ${ }^{58} \mathrm{~A}$ CLL-affected BM microenvironment would constitutively express various Wnt ligands, including Wnt3, 14, and $16 .{ }^{59}$ Experimental activation of $\beta$-catenin - the main transcriptional effector of canonical Wnt signaling pathway - protected CLL cells from spontaneous apoptosis. ${ }^{59} \mathrm{CLL}$ cells would highly express the Wnt receptor Frizzled3, and canonical Wnt pathway targets cyclin D1 and cyclin D2. ${ }^{60-62}$ Interestingly, the activation of these D cyclins in CD5+ B-cell lymphoproliferative disorders 
would identify diagnostic groups, with cyclin D1 levels significantly higher in $\zeta$ chain-associated protein 70 CLL cases, ie, patients with worse clinical outcome. ${ }^{60,63}$

Besides, experimental evidence suggests an aberrant activation of canonical Wnt signaling in CLL. For example, Wnt antagonist Dickkopf-related protein 1 malfunctioning was reported; ${ }^{64}$ and CLL cells abundantly express Wnt transcription factor lymphoid-enhancer binding factor 1 , normally downregulated in mature B-cells. ${ }^{65}$ Interestingly, unlike various cancers activating mutations of canonical Wnt signaling, including at $\beta$-catenin amino terminal, would be rare in CLL cells, ${ }^{66}$ indicating that Wnt signaling is triggered by ligands present in the BM microenvironment. Thus, although further studies are needed, canonical Wnt signaling may represent a good target for therapy in CLL. In addition, the transcription factor/lymphoid-enhancer binding factor/ $\beta$-catenin complex targets include genes regulating the transcription of various members of Notch and probably other antiapoptotic signaling pathways.${ }^{67,68}$ Conversely, there are also reports of Notch-mediated activation of Wnt transcription factor c-Myc, ${ }^{69}$ and other antiapoptotic signaling pathway downstream targets, including PTEN and PI3K/ Akt pathway, ${ }^{70}$ proinflammatory cytokines, ${ }^{24}$ and vascular endothelial growth factor (VEGF), ${ }^{71}$ either via physical interactions with pathway downstream molecules or by transcriptional regulation. This finding suggests the possibility of developing new classes of anticancer drugs targeting many antiapoptotic signaling pathways concomitantly. Such drugs would decrease the chemoresistance of CLL cells in vivo, which is probably due to the redundancy of antiapoptotic pathways, as already mentioned.

\section{Cell adhesion factors Integrins}

Experimental evidence indicates that integrins, which are transmembrane receptors mediating cell attachment to their surroundings, play key roles in many aspects of tissue localization of normal and malignant lymphocytes. CLL isolated from patients revealed good ability to interact with the endothelium. ${ }^{72}$ In this study, CLL cells displayed low level bounds to unstimulated endothelium through $\beta 2 /$ intercellular adhesion molecule, whereas endothelium stimulation allowed strong adhesion of the neoplastic population in $50 \%$ of cases, through VCAM-1, suggesting a role for endothelium activation in the initial events determining the entry of CLL cells into tissues. Notably, in another study, elevated serum levels of soluble VCAM-1 closely reflected tumor burden and other prognostic markers in a large cohort of untreated CLL patients, and was proposed as a marker in younger early-stage patients eligible for therapeutic trials. ${ }^{73}$

Moreover, experimental evidence indicates that leukemia cell binding to stromal cells requires the simultaneous action of $\beta 1$ - and $\beta 2$-integrins, though functional redundancy of cell adhesion molecules would also be present. For instance, in an in vitro study where CLL cells were co-cultured with BM stromal cells, although 30\%-50\% adhesion inhibition was obtained with the combination of anti-CD11a/CD18/CD29/ $\alpha_{4} \beta_{1}$, attempts to inhibit CLL cell adhesion using blocking antibodies targeting integrins failed. ${ }^{13}$ Strikingly, high levels of the antiapoptotic protein Bcl-2 were observed concomitantly and correlated positively with increases in the percentages of surviving CLL cells. Besides, blocking experiments with anti- $\alpha_{4} \beta_{1}$ integrin antibodies revealed that $\alpha_{4} \beta_{1}$ integrin confers resistance to fludarabine and cyclophosphamide by modulating Bcl-2, p53, and NF- $\mathrm{KB}$ in CLL cells co-cultured with BM MSCs, ${ }^{24,26,74}$ pointing out these molecules as potential therapeutic targets.

\section{CD44}

CD44 antigen, a cell surface glycoprotein involved in cell adhesion and migration, would play a key role in malignant cell homing and fibronectin synthesis in hairy cell leukemia, a subtype of CLL. ${ }^{75}$ However, the role of CD44 in CLL is poorly understood. Using a CLL murine model (E $\mu$-TCL1 transgenic mouse) and malignant cells from CLL patients, Fedorchenko et al recently investigated the functional role of CD44. ${ }^{76}$ The study revealed that CD44 expression in CLL is mediated by the tumor microenvironment, and CD44 appeared to promote leukemogenesis by regulating stimuli of myeloid cell leukemia 1 (Mcl1) expression, as a co-receptor. More specifically, deletion of CD44 during TCL1-driven murine leukemogenesis reduced the tumor burden and increased overall survival, anti-CD44 small interfering ribonucleic acids impaired tumor cell viability, whereas engagement of CD44 by its natural ligands, hyaluronic acid or chondroitin sulfate, protected CLL cells from apoptosis. Interestingly, the inhibitory anti-CD44 antibodies IM7 and A3D8 impaired the viability of CLL cells both in vitro and in vivo, suggesting CD44 as a potential therapeutic target in CLL. CLL cell apoptosis observed in presence of the aforementioned antibodies occurred following reduction of the anti-apoptotic Bcl-2 protein Mcl1 and the activation of caspase proapoptotic pathway.

CLL cell survival was prolonged in co-cultures with immortalized follicular dendritic cells via CD44-mediated direct cell contact. ${ }^{12,18}$ The latter was associated with Mcl1 
upregulation. Interestingly, increases in Mcll levels and altered regulations of the $\mathrm{Mcll}$ gene were associated with chemoresistance and worse prognosis, marked by rapid disease progression and shorter overall survival in CLL patients. ${ }^{36,77-79}$ Furthermore, many independent groups reported an association between decreases in Mcl1 levels in CLL cells and complete remission following chemotherapy. ${ }^{36,79,80}$ Not surprisingly, relatively recent reports pointed out the inhibition Bcl-2 family molecules as a promising approach for overcoming stroma-mediated treatment resistance in CLL. ${ }^{81-83}$ Similarly, CLL cell targeting with a monoclonal antibody specific for CD44 was also recently reported as a potential therapeutic approach in patients with worse prognosis (CLL patients expressing $\zeta$ chain-associated protein 70$).{ }^{84}$

\section{Inflammatory factors Cytokines}

BM stromal cells synthesize several cytokines, including IL-6, IL-7, and IL-10, and transforming growth factor- $\beta$, among others. These soluble factors play a role in BM stromal cellmediated survival and proliferation of CLL cells. ${ }^{85}$ CLL cells fail to migrate through the endothelium or stroma without cytokine stimulation in vitro, and the capacity of cytokines to modify integrin-mediated function would play a key role in the determination of the CLL clinical pattern. ${ }^{72}$ Plander et al elegantly demonstrated the existence of crosstalk between CLL cells and BM stromal cells where the first induce the upregulation of adhesion molecules and their ligands in the latter, along with an increased cytokine production in favor of CLL cell apoptosis resistance. ${ }^{86}$ Notably, significant increases in the survival rate of CLL cells cultured alone or co-cultured with BM MSCs were observed in presence of the proinflammatory cytokine IL-7, but not in presence of the mainly counter inflammatory cytokine IL- $6 .{ }^{85}$ Besides, a relatively recent study revealed that tumor necrosis factorrelated factors (B-cell activating factor, apoptosis-inducing ligand, and CD40 L) and other proinflammatory factors are key molecules for the bidirectional crosstalk between stromal endothelial cells and CLL cells. ${ }^{87}$ Interestingly, the abrogation of CD40 expression or suppression of B-cell activating factor and apoptosis-inducing ligand cleavases in endothelial cells reduced the survival and diversification of CLL cells, further indicating the potential of proinflammatory cytokinedependent factors as targets for CLL therapy. Furthermore, in a recent study where CLL patients were given green tea, whose constituents (mainly epigallocatechin gallate) reported antitumor effects, circulating regulatory T-cells were decreased in CLL patients with early-stage disease. Notably, both IL-10 and transforming growth factor- $\beta$ serum levels declined throughout the green tea intake period, in both patients and controls, indicating a role for these molecules in the pathogenesis of the disease. ${ }^{88}$

\section{Chemokines}

Stromal cells can also increase CLL cell survival by activating the homeostatic and lymphopoietic chemokine SDF-1 (CXCL12), its receptor CXCLR4, or the downstream molecules. ${ }^{89} \mathrm{SDF}-1$ is constitutively produced by stromal cells in vivo, ${ }^{90}$ and both CLL and BM stromal cells express the CXCR4 surface receptor. ${ }^{31} \mathrm{BM}$ stromal cells attract CLL cells via CXCR4 -mediated chemotaxis, ${ }^{18,91}$ suggesting a key role of the first in BM infiltration by the latter.

Besides, in co-cultures of CLL cells with blood-derived nurse-like cells, the chemokine SDF-1 appeared as one of the key factors accounting for the increase of malignant cell survival. ${ }^{11}$ Nurse-like cells also activated mitogen-activated protein kinases extracellular signal-regulated kinase $1 / 2$, and increased the antiapoptotic protein Mcl1 in CLL cells, probably through SDF-1-CXCR4 signaling. ${ }^{91}$ Interestingly, the disruption of the SDF-1-CXCR4 interaction by the CXCR4 inhibitor RCP168 abrogated the resistance of CLL cells to chemotherapy-induced apoptosis in vitro. ${ }^{92}$ Chemokine receptor inhibitor effects on CLL cells should be investigated in vivo, considering the implications for therapy.

\section{B-cell antigen receptor}

In addition to the stromal secretion of cytokines, chemokines, and the resulting expression of adhesion molecules, microenvironmental regulation of CLL cell survival may also be driven by antigenic stimulation through the B-cell antigen receptor. Binder et al showed that CLL B-cell antigen receptor stimulation by stroma-derived antigens can contribute to the protective effect that the stroma exerts on CLL cells, ${ }^{93}$ shedding new light on the complexity of the pathophysiology of the disease. Such complexity is probably due to the fact that CLL remains so far a mostly incurable disease. In addition, immunoglobulin heavy chain variable (IGHV) gene mutational status would represent a major prognostic marker in CLL, as patients with discordant mutational status may present a higher risk population. ${ }^{94}$ This finding may probably help improve stratification in clinical trials.

\section{Angiogenic factors}

Vascularization is a determinant factor of cell and tissue fate in both normal pathological conditions. In many 
hematological malignancies, aberrant neovascularization provides the neoplastic tissue with necessary substances for growth and expansion in the BM. VEGF family (VEGF-B, C, D), their receptors VEGFR1, 2, 3, and system Tie2/ angiopoietins are key players in such neovascularization. Not surprisingly, serum levels of VEGF as well as other angiogenic factors, like basic fibroblast growth factor and matrix metalloproteinase 9, are elevated in the serum of CLL patients and correlate with an unfavorable prognosis $;{ }^{95} \mathrm{BM}$ stromal cell-mediated survival of CLL cells in vitro was also severely impaired following blockade of matrix metalloproteinase 9 activity. Furthermore, the constitutive activation of the mitogen-activated protein kinase $\mathrm{p} 38$ would be critical for matrix metalloproteinase 9 production on BM stromal cells, indicating new therapeutic avenues. A more recent report also suggested that hepatocyte growth factor and its receptor (c-Met) prolong the survival of CLL cells through signal transducer and activator of transcription 3 phosphorylation. ${ }^{96}$ In this study, gene expression profile analysis revealed that soluble hepatocyte growth factor and SDF-1 were produced mainly by mesenchymal lineages, pointing out a potential role of MSCs in the disease in addition to BM stromal cells, fibroblasts, trabecular bone-derived cells, and osteoblast-like cell lines that also supported CLL survival in vitro.

Other studies of co-cultures of BM stromal cells and CLL cells revealed a marked upregulation of PI3K/NF- $\kappa B$ prosurvival pathway genes, which mediated a proangiogenic switch in CLL cells via upregulation of VEGF and osteopontin, and downregulation of the anti-angiogenic molecule thrombospondin-1.97,98 However, a recent report from Gupta et al revealed that the proteasome inhibitor carfilzomib induces cytotoxicity through an atypical NF- $\mathrm{KB}$ response in CLL, ${ }^{99}$ further indicating the complexity of prosurvival strategies in that malignancy. Characterizing the NF- $\kappa B$ role in CLL may provide new avenues for therapy. Moreover, a PI3K inhibitor (GS-1101/CAL-101) attenuated pathway signaling, induced apoptosis, overcame signals from the microenvironment, ${ }^{100}$ and decreased mitochondrial apoptotic priming underlying stroma-mediated treatment resistance ${ }^{82}$ in various cellular models of Hodgkin's lymphoma. Another PI3K inhibitor (ON 01910.Na) induced CLL cell death through a dual mechanism of action involving PI3K/Akt inhibition and induction of oxidative stress. ${ }^{101} \mathrm{PI} 3 \mathrm{~K}$ inhibitors should be investigated further as therapeutic agents in CLL.

\section{Conclusion}

The ongoing efforts to develop therapies against CLL have provided a better understanding of the stromal factors allowing malignant cells to escape spontaneous and chemotherapy-mediated apoptosis. Emerging experimental evidence suggests that malignant cell interaction with BM microenvironment plays a key role in CLL pathogenesis and is a determinant factor for disease poor prognosis. Infiltrating CLL cells are permanently in contact with resident stromal cells in the BM and lymph nodes. Co-culture studies have revealed that BM MSCs and other stromal cell types confer CLL cells the ability to resist both spontaneous and anticancer drug-induced apoptosis, as well as maintenance and proliferation abilities. Overall, these studies suggest the existence of a complex network of antiapoptotic and prosurvival molecules, including at least cell adhesion, proinflammatory, angiogenic, and proto-oncogenic molecules, supporting infiltrating malignant cells and neoplastic tissue maintenance in the CLLaffected BM. Interestingly, mounting evidence indicates that many prosurvival signaling pathways potentially sustaining CLL cell maintenance in the BM interact with one another. Thus, it appears that developing new classes of drugs affecting many signaling pathways simultaneously, and therefore abrogating signaling redundancy-associated chemoresistance to classical anticancer drugs, is feasible. Future studies focusing on developing such drugs would provide efficient therapeutics against CLL and related chemoresistant hematologic malignancies.

\section{Acknowledgments}

Authors thank the colleagues of their respective institutions for their comments on the manuscript. Special thanks are due to Professor Mazzini.

\section{Disclosure}

The authors report no conflicts of interest in this work.

\section{References}

1. Chiorazzi N, Rai KR, Ferrarini M. Chronic lymphocytic leukemia. NEngl J Med. 2005;352(8):804-815.

2. Nagasawa T. Microenvironmental niches in the bone marrow required for B-cell development. Nat Rev Immunol. 2006;6(2):107-116.

3. Cordone I, Masi S, Mauro FR, et al. p53 expression in B-cell chronic lymphocytic leukemia: a marker of disease progression and poor prognosis. Blood. 1998;91(11):4342-4349.

4. Hoellenriegel J, Meadows SA, Sivina M, et al. The phosphoinositide 3'-kinase delta inhibitor, CAL-101, inhibits B-cell receptor signaling and chemokine networks in chronic lymphocytic leukemia. Blood. 2011;118(13):3603-3612.

5. Leong KG, Karsan A. Recent insights into the role of Notch signaling in tumorigenesis. Blood. 2006;107(6):2223-2233.

6. Artavanis-Tsakonas S, Rand MD, Lake RJ. Notch signaling: cell fate control and signal integration in development. Science. 1999;284(5415): 770-776.

7. Miele L, Osborne B. Arbiter of differentiation and death: Notch signaling meets apoptosis. J Cell Physiol. 1999;181(3):393-409. 
8. Nwabo Kamdje AH, Mosna F, Bifari F, et al. Notch-3 and Notch-4 signaling rescue from apoptosis human B-ALL cells in contact with human bone marrow-derived mesenchymal stromal cells. Blood. 2011;118(2): 380-389.

9. da Silva Meirelles L, Chagastelles PC, Nardi NB. Mesenchymal stem cells reside in virtually all post-natal organs and tissues. J Cell Sci. 2006;119(Pt 11):2204-2213.

10. Krampera M, Sartoris S, Liotta F, et al. Immune regulation by mesenchymal stem cells derived from adult spleen and thymus. Stem Cells Dev. 2007;16(5):797-810.

11. Burger JA, Tsukada N, Burger M, Zvaifler NJ, Dell'Aquila M, Kipps TJ. Blood-derived nurse-like cells protect chronic lymphocytic leukemia B cells from spontaneous apoptosis through stromal cell-derived factor-1. Blood. 2000;96(8):2655-2663.

12. Pedersen IM, Kitada S, Leoni LM, et al. Protection of CLL B cells by a follicular dendritic cell line is dependent on induction of Mcl-1. Blood. 2002;100(5):1795-1801.

13. Lagneaux L, Delforge A, Bron D, De Bryun C, Stryckmans P. Chronic lymphocytic leukemic B cells but not normal B cells are rescued from apoptosis by contact with normal bone marrow stromal cells. Blood. 1998;91(7):2387-2396.

14. Caligaris-Cappio F, Hamblin TJ. B-cell chronic lymphocytic leukemia: a bird of a different feather. J Clin Oncol. 1999;17(1):399-408.

15. Panayiotidis P, Jones D, Ganeshaguru K, Foroni L, Hoffbrand AV. Human bone marrow stromal cells prevent apoptosis and support the survival of chronic lymphocytic leukaemia cells in vitro. Br J Haematol. 1996;92(1):97-103.

16. Gluck U, Zipori D, Wetzler M, et al. Long-term proliferation of human leukemia cells induced by mouse stroma. Exp Hematol. 1989;17(5): 398-404.

17. Ding W, Nowakowski GS, Knox TR, et al. Bi-directional activation between mesenchymal stem cells and CLL B-cells: implication for CLL disease progression. Br J Haematol. 2009;147(4):471-483.

18. Mohle R, Failenschmid C, Bautz F, Kanz L. Overexpression of the chemokine receptor CXCR4 in B cell chronic lymphocytic leukemia is associated with increased functional response to stromal cell-derived factor-1 (SDF-1). Leukemia. 1999;13(12):1954-1959.

19. Wekerle H, Ketelsen UP, Ernst M. Thymic nurse cells. Lymphoepithelial cell complexes in murine thymuses: morphological and serological characterization. J Exp Med. 1980;151(4):925-944.

20. Han T, Barcos M, Emrich L, et al. Bone marrow infiltration patterns and their prognostic significance in chronic lymphocytic leukemia: correlations with clinical, immunologic, phenotypic, and cytogenetic data. J Clin Oncol. 1984;2(6):562-570.

21. Pangalis GA, Roussou PA, Kittas C, et al. Patterns of bone marrow involvement in chronic lymphocytic leukemia and small lymphocytic (well differentiated) non-Hodgkin's lymphoma. Its clinical significance in relation to their differential diagnosis and prognosis. Cancer. 1984;54(4):702-708.

22. Burger M, Hartmann T, Krome M, et al. Small peptide inhibitors of the CXCR4 chemokine receptor (CD184) antagonize the activation, migration, and antiapoptotic responses of CXCL12 in chronic lymphocytic leukemia B cells. Blood. 2005;106(5):1824-1830.

23. Balakrishnan K, Burger JA, Wierda WG, Gandhi V. AT-101 induces apoptosis in CLL B cells and overcomes stromal cell-mediated Mcl-1 induction and drug resistance. Blood. 2009;113(1): 149-153.

24. de la Fuente MT, Casanova B, Cantero E, et al. Involvement of p53 in $\alpha 4 \beta 1$ integrin-mediated resistance of B-CLL cells to fludarabine. Biochem Biophys Res Commun. 2003;311(3):708-712.

25. Damiano JS, Dalton WS. Integrin-mediated drug resistance in multiple myeloma. Leuk Lymphoma. 2000;38(1-2):71-81.

26. de la Fuente MT, Casanova B, Moyano JV, et al. Engagement of $\alpha 4 \beta 1$ integrin by fibronectin induces in vitro resistance of $\mathrm{B}$ chronic lymphocytic leukemia cells to fludarabine. J Leukoc Biol. 2002;71(3): 495-502.
27. Robertson LE, Chubb S, Meyn RE, et al. Induction of apoptotic cell death in chronic lymphocytic leukemia by 2 -chloro- 2 -deoxyadenosine and 9- $\beta$-D-arabinosyl-2-fluoroadenine. Blood. 1993;81(1): $143-150$.

28. Schwanen $C$, Hecker T, Hubinger G, et al. In vitro evaluation of bendamustine induced apoptosis in B-chronic lymphocytic leukemia. Leukemia. 2002;16(10):2096-2105

29. Zhang W, Trachootham D, Liu J, et al. Stromal control of cystine metabolism promotes cancer cell survival in chronic lymphocytic leukaemia. Nat Cell Biol. 2012;14(3):276-286.

30. Evans SM, Schrlau AE, Chalian AA, Zhang P, Koch CJ. Oxygen levels in normal and previously irradiated human skin as assessed by EF5 binding. J Invest Dermatol. 2006;126(12):2596-2606.

31. Gustafsson MV, Zheng X, Pereira T, et al. Hypoxia requires notch signaling to maintain the undifferentiated cell state. Dev Cell. 2005; 9(5):617-628.

32. Hamidi H, Gustafason D, Pellegrini M, Gasson J. Identification of novel targets of CSL-dependent Notch signaling in hematopoiesis. PLoS One. 2011;6(5):e20022.

33. Kanamori E, Itoh M, Tojo N, Koyama T, Nara N, Tohda S. Flow cytometric analysis of Notch 1 and Jagged1 expression in normal blood cells and leukemia cells. Exp Ther Med. 2012;4(3):397-400.

34. Rosati E, Sabatini R, Rampino G, et al. Constitutively activated Notch signaling is involved in survival and apoptosis resistance of B-CLL cells. Blood. 2009;113(4):856-865.

35. Hajdu M, Sebestyen A, Barna G, et al. Activity of the notch-signalling pathway in circulating human chronic lymphocytic leukaemia cells. Scand J Immunol. 2007;65(3):271-275.

36. Di Ianni M, Baldoni S, Rosati E, et al. A new genetic lesion in B-CLL: a NOTCH1 PEST domain mutation. Br J Haematol. 2009;146(6): 689-691.

37. Fabbri G, Rasi S, Rossi D, et al. Analysis of the chronic lymphocytic leukemia coding genome: role of NOTCH1 mutational activation. J Exp Med. 2011;208(7):1389-1401.

38. Willander K, Dutta RK, Ungerback J, et al. NOTCH1 mutations influence survival in chronic lymphocytic leukemia patients. BMC Cancer. 2013;13:274.

39. Baldoni S, Sportoletti P, Del Papa B, et al. NOTCH and NF- $\kappa$ B interplay in chronic lymphocytic leukemia is independent of genetic lesion. Int J Hematol. 2013;98(2):153-157.

40. Weng AP, Millholland JM, Yashiro-Ohtani Y, et al. c-Myc is an important direct target of Notch1 in T-cell acute lymphoblastic leukemia/ lymphoma. Genes Dev. 2006;20(15):2096-2109.

41. Secchiero P, Melloni E, di Iasio MG, et al. Nutlin-3 up-regulates the expression of Notch1 in both myeloid and lymphoid leukemic cells, as part of a negative feedback antiapoptotic mechanism. Blood. 2009;113(18):4300-4308.

42. Redondo-Munoz J, Escobar-Diaz E, Samaniego R, Terol MJ, GarciaMarco JA, Garcia-Pardo A. MMP-9 in B-cell chronic lymphocytic leukemia is up-regulated by $\alpha 4 \beta 1$ integrin or CXCR4 engagement via distinct signaling pathways, localizes to podosomes, and is involved in cell invasion and migration. Blood. 2006;108(9):3143-3151.

43. Wickremasinghe RG, Prentice AG, Steele AJ. p53 and Notch signaling in chronic lymphocytic leukemia: clues to identifying novel therapeutic strategies. Leukemia. 2011;25(9):1400-1407.

44. Nwabo Kamdje AH, Bassi G, Pacelli L, et al. Role of stromal cellmediated Notch signaling in CLL resistance to chemotherapy. Blood Cancer J. 2012;2(5):e73.

45. Hubmann R, Hilgarth M, Schnabl S, et al. Gliotoxin is a potent NOTCH2 transactivation inhibitor and efficiently induces apoptosis in chronic lymphocytic leukaemia (CLL) cells. Br J Haematol. 2013;160(5): 618-629.

46. Rosati E, Sabatini R, De Falco F, et al. $\gamma$-Secretase inhibitor I induces apoptosis in chronic lymphocytic leukemia cells by proteasome inhibition, endoplasmic reticulum stress increase and notch down-regulation. Int J Cancer. 2013;132(8):1940-1953. 
47. Duman-Scheel M, Weng L, Xin S, Du W. Hedgehog regulates cell growth and proliferation by inducing cyclin D and cyclin E. Nature. 2002;417(6886):299-304.

48. Dierks C, Grbic J, Zirlik K, et al. Essential role of stromally induced hedgehog signaling in B-cell malignancies. Nat Med. 2007;13(8): 944-951.

49. Lee J, Platt KA, Censullo P, Ruiz i Altaba A. Gli1 is a target of Sonic hedgehog that induces ventral neural tube development. Development. 1997;124(13):2537-2552.

50. Bhardwaj G, Murdoch B, Wu D, et al. Sonic hedgehog induces the proliferation of primitive human hematopoietic cells via BMP regulation. Nat Immunol. 2001;2(2):172-180.

51. Mar BG, Amakye D, Aifantis I, Buonamici S. The controversial role of the Hedgehog pathway in normal and malignant hematopoiesis. Leukemia. 2011;25(11):1665-1673.

52. Hegde GV, Munger CM, Emanuel K, et al. Targeting of sonic HedgehogGli signaling: a potential strategy to improve therapy for mantle cell lymphoma. Mol Cancer Ther. 2008;7(6):1450-1460.

53. Hegde GV, Peterson KJ, Emanuel K, et al. Hedgehog-induced survival of B-cell chronic lymphocytic leukemia cells in a stromal cell microenvironment: a potential new therapeutic target. Mol Cancer Res. 2008;6(12):1928-1936.

54. Hofmann I, Stover EH, Cullen DE, et al. Hedgehog signaling is dispensable for adult murine hematopoietic stem cell function and hematopoiesis. Cell Stem Cell. 2009;4(6):559-567.

55. Cadigan KM, Nusse R. Wnt signaling: a common theme in animal development. Genes Dev. 1997;11(24):3286-3305.

56. Logan CY, Nusse R. The Wnt signaling pathway in development and disease. Annu Rev Cell Dev Biol. 2004;20:781-810.

57. De Boer J, Wang HJ, Van Blitterswijk C. Effects of Wnt signaling on proliferation and differentiation of human mesenchymal stem cells. Tissue Eng. 2004;10(3-4):393-401.

58. Gregory CA, Perry AS, Reyes E, Conley A, Gunn WG, Prockop DJ. Dkk-1-derived synthetic peptides and lithium chloride for the control and recovery of adult stem cells from bone marrow. J Biol Chem. 2005;280(3):2309-2323.

59. Lu D, Zhao Y, Tawatao R, et al. Activation of the Wnt signaling pathway in chronic lymphocytic leukemia. Proc Natl Acad Sci USA. 2004;101(9):3118-3123.

60. Meyerson HJ, MacLennan G, Husel W, et al. D cyclins in CD5+ B-cell lymphoproliferative disorders: cyclin D1 and cyclin D2 identify diagnostic groups and cyclin D1 correlates with ZAP-70 expression in chronic lymphocytic leukemia. Am J Clin Pathol. 2006;125(2):241-250.

61. Igawa T, Sato Y, Takata K, et al. Cyclin D2 is overexpressed in proliferation centers of chronic lymphocytic leukemia/small lymphocytic lymphoma. Cancer Sci. 2011;102(11):2103-2107.

62. Lu D, Choi MY, Yu J, Castro JE, Kipps TJ, Carson DA. Salinomycin inhibits Wnt signaling and selectively induces apoptosis in chronic lymphocytic leukemia cells. Proc Natl Acad Sci U S A. 2011;108(32): 13253-13257.

63. Slack GW, Wizniak J, Dabbagh L, Shi X, Gelebart P, Lai R. Flow cytometric detection of ZAP-70 in chronic lymphocytic leukemia: correlation with immunocytochemistry and Western blot analysis. Arch Pathol Lab Med. 2007;131(1):50-56.

64. Filipovich A, Gandhirajan RK, Gehrke I, Poll-Wolbeck SJ, Kreuzer KA. Evidence for non-functional Dickkopf-1 (DKK-1) signaling in chronic lymphocytic leukemia (CLL). Eur J Haematol. 2010; 85(4):309-313.

65. Howe D, Bromidge T. Variation of LEF-1 mRNA expression in lowgrade B-cell non-Hodgkin's lymphoma. Leuk Res. 2006;30(1):29-32.

66. Ge X, Wang X. Role of Wnt canonical pathway in hematological malignancies. J Hematol Oncol. 2010;3:33.

67. Hayward P, Kalmar T, Arias AM. Wnt/Notch signalling and information processing during development. Development. 2008;135(3):411-424.

68. Radtke F, Clevers H. Self-renewal and cancer of the gut: two sides of a coin. Science. 2005;307(5717):1904-1909.
69. Palomero T, Lim WK, Odom DT, et al. NOTCH1 directly regulates c-MYC and activates a feed-forward-loop transcriptional network promoting leukemic cell growth. Proc Natl Acad Sci U S A. 2006;103(48): 18261-18266.

70. Palomero T, Dominguez M, Ferrando AA. The role of the PTEN/ AKT pathway in NOTCH1-induced leukemia. Cell Cycle. 2008;7(8): 965-970.

71. Gutierrez A Jr, Tschumper RC, Wu X, et al. LEF-1 is a prosurvival factor in chronic lymphocytic leukemia and is expressed in the preleukemic state of monoclonal B-cell lymphocytosis. Blood. 2010;116(16): 2975-2983.

72. Vincent AM, Cawley JC, Burthem J. Integrin function in chronic lymphocytic leukemia. Blood. 1996;87(11):4780-4788.

73. Christiansen I, Sundstrom C, Totterman TH. Elevated serum levels of soluble vascular cell adhesion molecule-1 (sVCAM-1) closely reflect tumour burden in chronic B-lymphocytic leukaemia. Br J Haematol. 1998;103(4):1129-1137.

74. Lutzny G, Kocher T, Schmidt-Supprian M, et al. Protein kinase c- $\beta$ dependent activation of NF- $\mathrm{\kappa B}$ in stromal cells is indispensable for the survival of chronic lymphocytic leukemia B cells in vivo. Cancer Cell. 2013;23(1):77-92.

75. Aziz KA, Till KJ, Zuzel M, Cawley JC. Involvement of CD44-hyaluronan interaction in malignant cell homing and fibronectin synthesis in hairy cell leukemia. Blood. 2000;96(9):3161-3167.

76. Fedorchenko O, Stiefelhagen M, Peer-Zada AA, et al. CD44 regulates the apoptotic response and promotes disease development in chronic lymphocytic leukemia. Blood. 2013;121(20):4126-4136.

77. Petrasch S, Brittinger G, Wacker HH, Schmitz J, Kosco-Vilbois M Follicular dendritic cells in non-Hodgkin's lymphomas. Leuk Lymphoma. 1994;15(1-2):33-43.

78. Choe J, Li L, Zhang X, Gregory CD, Choi YS. Distinct role of follicular dendritic cells and $\mathrm{T}$ cells in the proliferation, differentiation, and apoptosis of a centroblast cell line, L3055. J Immunol. 2000;164(1): 56-63

79. Lee SY, Kumano K, Nakazaki K, et al. Gain-of-function mutations and copy number increases of Notch2 in diffuse large B-cell lymphoma. Cancer Sci. 2009;100(5):920-926.

80. Sportoletti P, Baldoni S, Cavalli L, et al. NOTCH1 PEST domain mutation is an adverse prognostic factor in B-CLL. Br J Haematol. 2010;151(4):404-406.

81. Bates DJ, Danilov AV, Lowrey CH, Eastman A. Vinblastine rapidly induces NOXA and acutely sensitizes primary chronic lymphocytic leukemia cells to ABT-737. Mol Cancer Ther. 2013;12(8): 1504-1514

82. Davids MS, Deng J, Wiestner A, et al. Decreased mitochondrial apoptotic priming underlies stroma-mediated treatment resistance in chronic lymphocytic leukemia. Blood. 2012;120(17):3501-3509.

83. Soderquist R, Bates DJ, Danilov AV, Eastman A. Gossypol overcomes stroma-mediated resistance to the BCL2 inhibitor ABT-737 in chronic lymphocytic leukemia cells ex vivo. Leukemia. Epub May 3, 2013.

84. Zhang S, Wu CC, Fecteau JF, et al. Targeting chronic lymphocytic leukemia cells with a humanized monoclonal antibody specific for CD44. Proc Natl Acad Sci U S A. 2013;110(15):6127-6132.

85. Long BW, Witte PL, Abraham GN, Gregory SA, Plate JM. Apoptosis and interleukin 7 gene expression in chronic B-lymphocytic leukemia cells. Proc Natl Acad Sci U S A. 1995;92(5):1416-1420.

86. Plander M, Ugocsai P, Seegers S, et al. Chronic lymphocytic leukemia cells induce anti-apoptotic effects of bone marrow stroma. Ann Hematol. 2011;90(12):1381-1390.

87. Cols M, Barra CM, He B, et al. Stromal endothelial cells establish a bidirectional crosstalk with chronic lymphocytic leukemia cells through the TNF-related factors BAFF, APRIL, and CD40L. J Immunol. 2012;188(12):6071-6083.

88. D'Arena G, Simeon V, De Martino L, et al. Regulatory T-cell modulation by green tea in chronic lymphocytic leukemia. Int J Immunopathol Pharmacol. 2013;26(1):117-125. 
89. Nagasawa T, Kikutani H, Kishimoto T. Molecular cloning and structure of a pre-B-cell growth-stimulating factor. Proc Natl Acad Sci US A. 1994;91(6):2305-2309.

90. Bleul CC, Fuhlbrigge RC, Casasnovas JM, Aiuti A, Springer TA. A highly efficacious lymphocyte chemoattractant, stromal cell-derived factor 1 (SDF-1). J Exp Med. 1996;184(3):1101-1109.

91. Burger JA, Burger M, Kipps TJ. Chronic lymphocytic leukemia $\mathrm{B}$ cells express functional CXCR4 chemokine receptors that mediate spontaneous migration beneath bone marrow stromal cells. Blood. 1999;94(11):3658-3667.

92. Zeng Z, Samudio IJ, Munsell M, et al. Inhibition of CXCR4 with the novel RCP168 peptide overcomes stroma-mediated chemoresistance in chronic and acute leukemias. Mol Cancer Ther. 2006;5(12): 3113-3121.

93. Binder M, Lechenne B, Ummanni R, et al. Stereotypical chronic lymphocytic leukemia B-cell receptors recognize survival promoting antigens on stromal cells. PloS One. 2010;5(12):e15992.

94. Visco C, Moretta F, Falisi E, et al. Double productive immunoglobulin sequence rearrangements in patients with chronic lymphocytic leukemia. Am J Hematol. 2013;88(4):277-282.

95. Ringshausen I, Dechow T, Schneller F, et al. Constitutive activation of the MAPkinase p38 is critical for MMP-9 production and survival of B-CLL cells on bone marrow stromal cells. Leukemia. 2004;18(12): 1964-1970.

96. Giannoni P, Scaglione S, Quarto R, et al. An interaction between hepatocyte growth factor and its receptor (c-MET) prolongs the survival of chronic lymphocytic leukemic cells through STAT3 phosphorylation: a potential role of mesenchymal cells in the disease. Haematologica. 2011;96(7):1015-1023.

97. Kay NE, Shanafelt TD, Byrd JC, Grever MR. Community-based Phase II trial of PCR for CLL/SLL patients. Cancer Biother Radiopharm. 2007;22(5):713-714; author reply 715-717.

98. Edelmann J, Klein-Hitpass L, Carpinteiro A, et al. Bone marrow fibroblasts induce expression of PI $3 \mathrm{~K} / \mathrm{NF}-\kappa \mathrm{B}$ pathway genes and a pro-angiogenic phenotype in CLL cells. Leuk Res. 2008;32(10): $1565-1572$.

99. Gupta SV, Hertlein E, Lu Y, et al. The proteasome inhibitor carfilzomib functions independently of p53 to induce cytotoxicity and an atypical NF- $\kappa \mathrm{B}$ response in chronic lymphocytic leukemia cells. Clin Cancer Res. 2013;19(9):2406-2419.

100. Meadows SA, Vega F, Kashishian A, et al. PI3K $\delta$ inhibitor, GS-1101 (CAL-101), attenuates pathway signaling, induces apoptosis, and overcomes signals from the microenvironment in cellular models of Hodgkin lymphoma. Blood. 2012;119(8):1897-1900.

101. Chapman CM, Sun X, Roschewski M, et al. ON 01910.Na is selectively cytotoxic for chronic lymphocytic leukemia cells through a dual mechanism of action involving PI3K/AKT inhibition and induction of oxidative stress. Clin Cancer Res. 2012;18(7):1979-1991.

102. Van Den Neste E, Cazin B, Janssens A, et al. Acadesine for patients with relapsed/refractory chronic lymphocytic leukemia (CLL): a multicenter Phase I/II study. Cancer Chemother Pharmacol. 2013;71(3):581-591.

103. Hosing C, Kebriaei P, Wierda W, Jena B, Cooper LJ, Shpall E. CARs in chronic lymphocytic leukemia - ready to drive. Curr Hematol Malig Rep. 2013;8(1):60-70.
104. Macias-Perez IM, Flinn IW. GS-1101: a $\delta$-specific PI3K inhibitor in chronic lymphocytic leukemia. Curr Hematol Malig Rep. 2013;8(1): 22-27.

105. Byrd JC, Furman RR, Coutre SE, et al. Targeting BTK with ibrutinib in relapsed chronic lymphocytic leukemia. New Engl J Med. 2013;369(1): $32-42$.

106. Brown JR. Ibrutinib (PCI-32765), the first BTK (Bruton's tyrosine kinase) inhibitor in clinical trials. Curr Hematol Malig Rep. 2013;8(1): $1-6$.

107. Friedman DR, Lanasa MC, Davis PH, et al. Perifosine treatment in chronic lymphocytic leukemia: Results of a Phase II clinical trial and in vitro studies. Leuk Lymphoma. Epub July 17, 2013.

108. Mahadevan D, Chiorean EG, Harris WB, et al. Phase I pharmacokinetic and pharmacodynamic study of the pan-PI3K/mTORC vascular targeted pro-drug SF1126 in patients with advanced solid tumours and B-cell malignancies. Eur J Cancer. 2012;48(18):3319-3327.

109. Tsimberidou AM, Wierda WG, Wen S, et al. Phase I-II clinical trial of oxaliplatin, fludarabine, cytarabine, and rituximab therapy in aggressive relapsed/refractory chronic lymphocytic leukemia or Richter syndrome. Clin Lymphoma Myeloma Leuk. Epub June 26, 2013.

110. Krejci M, Doubek M, Brychtova Y, et al. Fludarabine with cytarabine followed by reduced-intensity conditioning and allogeneic hematopoietic stem cell transplantation in patients with poor-risk chronic lymphocytic leukemia. Ann Hematol. 2013;92(2):249-254.

111. Woyach JA, Ruppert AS, Rai K, et al. Impact of age on outcomes after initial therapy with chemotherapy and different chemoimmunotherapy regimens in patients with chronic lymphocytic leukemia: results of sequential cancer and leukemia group B studies. J Clin Oncol. 2013;31(4):440-447.

112. Knauf WU, Lissitchkov T, Aldaoud A, et al. Bendamustine compared with chlorambucil in previously untreated patients with chronic lymphocytic leukaemia: updated results of a randomized Phase III trial. Br J Haematol. 2012;159(1):67-77.

113. Badoux XC, Keating MJ, Wen S, et al. Phase II study of lenalidomide and rituximab as salvage therapy for patients with relapsed or refractory chronic lymphocytic leukemia. J Clin Oncol. 2013;31(5):584-591.

114. Michallet M, Socie G, Mohty M, et al. Rituximab, fludarabine, and total body irradiation as conditioning regimen before allogeneic hematopoietic stem cell transplantation for advanced chronic lymphocytic leukemia: long-term prospective multicenter study. Exp Hematol. 2013;41(2):127-133.

115. Timmerman JM, Byrd JC, Andorsky DJ, et al. A Phase I dose-finding trial of recombinant interleukin-21 and rituximab in relapsed and refractory low grade B-cell lymphoproliferative disorders. Clin Cancer Res. 2012;18(20):5752-5760.

116. Fischer K, Cramer P, Busch R, et al. Bendamustine in combination with rituximab for previously untreated patients with chronic lymphocytic leukemia: a multicenter Phase II trial of the German Chronic Lymphocytic Leukemia Study Group. J Clin Oncol. 2012;30(26): 3209-3216.
Research and Reports in Biology

\section{Publish your work in this journal}

Research and Reports in Biology is an international, peer-reviewed, open access journal publishing original research, reports, editorials, reviews and commentaries on all areas of biology including animal biology, biochemical biology, cell biology, ecological studies, evolutionary biology, molecular biology, plant science and botany. The

\section{Dovepress}

manuscript management system is completely online and includes a very quick and fair peer-review system. Visit http://www.dovepress. com/testimonials.php to read real quotes from published authors. 